\begin{tabular}{|l|c|c|}
\hline \multicolumn{2}{|c|}{ DJS Vol. 38 (2017) 33-42 } & Delta Journal of Science \\
\hline Research Article & Available online at & \\
\hline
\end{tabular}

\title{
COORDINATED SEARCH FOR A RANDOMLY LOCATED TARGET
}

\author{
Abd El-moneim A. M. Teamah' ${ }^{1}$, Hamdy M. Abou Gabal ${ }^{2}$ and Walaa .A. Afifi ${ }^{3}$, \\ 1,2,3Department of Mathematics, \\ Faculty of science \\ Tanta university, Tanta,Egypt
}

\begin{abstract}
The coordinated search problem faced by two searchers who start together from some point on the line in order to search for a lost target which randomly located on the line. In this paper the distribution of the lost target is symmetric around the point of the intersection of two lines, where the intersected point is a starting point of the motion of the searchers. There are four searchers start together the search for the lost target at the intersection point under this condition we defined the search plan and computed the expected value of the first meeting time between one of the searchers and the target. The search plan which minimized this first meeting time is studied. Finally we obtained some special cases for a search problems. An illustrative examples is given to demonstrate the applicability of this model.
\end{abstract}

Key words: symmetric distribution, Located target, coordinated search

\section{Introduction:}

The study of search plans for any lost target either located or moved and having symmetric or unsymmetric distribution is important and has recently various applications, such as searching for a faulty unit in large linear system, such as electrical power lines, this kind of search is called linear search problem,(see [2], [4], [5] and [6]).

The coordinated search technique is one of a set of techniques, which studied on the line when the target has symmetric or unsymmetric distribution, (see [7], [8], [9] and [10]). Stone studied the located target on a known region, like petrol or gas supply underground, (see [12]). Also, the search for a located target in the plane and has symmetric or unsymmetric distribution has been studied see [1] and [3]. The search for a moving target like missing boats, submarines and missing system, a Bayesian approach would formulate for a target whose prior distribution and probabilistic motion model are known and generalized the approach for multi-vehicle search, (see [13] and [14]).

Let $\mathrm{X}$ be a random variable which represented the position of the target if it on the first line $\mathrm{L}_{1}$, and $\mathrm{Y}$ be a random variable which represented the position of the target if it on the second line $\mathrm{L}_{2}$, we have two searchers $\mathrm{S}_{1}$ and $S_{2}$ on the first line $L_{1}$. Also, we have another two searchers $S_{3}$ and $S_{4}$ on the second line $\mathrm{L}_{2}$. The four searchers $\mathrm{S}_{1}, \mathrm{~S}_{2}, \mathrm{~S}_{3}$ and $\mathrm{S}_{4}$ start together looking for the target 
from the point of the intersection of the two lines, on the first line $\mathrm{L}_{1}$ the searcher $\mathrm{S}_{1}$ searches to the right of the intersection point and the searcher $S_{2}$ searches to the left of the intersection point. Also, on the second line $\mathrm{L}_{2}$ the searcher $\mathrm{S}_{3}$ searches to the right of the intersection point and the searcher $\mathrm{S}_{4}$ searches to the left of the intersection point, either the two searchers $S_{1}$ and $S_{2}$ detect the target on the first line $\mathrm{L}_{1}$ or the other two searchers $S_{3}$ and $S_{4}$ detect the target on the second line $L_{2}$.

The four searchers return to the intersection point after searching successively common distances until the target is found. We assume that the speeds of the searchers are $\mathrm{V}_{1}, \mathrm{~V}_{2}, \mathrm{~V}_{3}$ and $\mathrm{V}_{4}$. Our aim is to calculate the first meeting time between one of the 4 searchers and the lost target. Also, we wish to find the optimal search plan which minimize the expected value.

\section{Search plan}

The generalized coordinated search problem asks how the four searchers who start together at the point of the intersection of two lines in a search region can minimize the expected time to meet back at the starting point after finding the lost target. The target is located according to a known symmetric distribution on one of two intersected lines $L_{1}$ and $L_{2}$, where the symmetric distribution of the target on $L_{1}$ is differs from the symmetric distribution of the target on $L_{2}$. The point of the intersection of the two lines is some point $a_{0}=b_{0}$, where $a_{0}$ refers to the distance which the first searcher $S_{1}$ far from the origin of $L_{1}$, and $b_{0}$ refers to the distance which the second searcher $S_{2}$ far from the origin of $L_{1}$. Also, $a_{0}$ is the position of $S_{1}$ on $L_{1}$ at the beginning of search and $b_{0}$ is the position of $S_{2}$, on $L_{1}$ at the beginning of search. Let $k_{0}=z_{0}$, where $k_{0}$ refer to the distance which the third searcher $S_{3}$ far from the origin of $L_{2}$, and $z_{0}$ refer to the distance which the fourth searcher $S_{4}$ far from the origin of $L_{2}$. Also, $k_{0}$ is the position of $S_{3}$ on $L_{2}$ at the beginning of search and $z_{0}$ is the position $S_{4}$ on $L_{2}$ at the beginning of search .

The point of the intersection of the two lines is some point $e_{1}$ at which $a_{0}=b_{0}$ on $L_{1}$, and $e_{2}$ at which $k_{0}=z_{0}$ on $L_{2}$. The probable paths for the searchers $S_{1}, S_{2}, S_{3}$ and $\mathrm{S}_{4}$ take the following cases:

Case(1),

in this case we have $e_{1}>0$ and $e_{2}>0$ Case(2),

in this case we have $e_{1}>0$ and $e_{2}<0$ Case(3), in this cas
Case $(4)$

in this case we have

Case(5),

in this case we have

Case(6),

in this case we have

Case(7),

in this case we have $e_{1}<0$ and $e_{2}=0$

Case (8),

in this case we have $e_{1}=0$ and $e_{2}<0$

Case(9),

in this case we have $\quad e_{1}=0$ and $e_{2}>0$

On $L_{1}$ the two searchers $S_{1}$ and $S_{2}$ follow the search paths a and $b$, respectively to detect the target. The search path a of $S_{1}$ is completely defined by a sequence $\left\{a_{i}, i \geq 0\right\}$ and the search path b of $S_{2}$ is completely defined by a sequence $\left\{b_{i}, i \geq 0\right\}$ where $\mathrm{i}$ is a nonnegative integer. let the search plan be represented by $\phi=\left\{a_{i}, b_{i}\right\} €$ $\Phi_{1}$, where $\Phi_{1}$ is the set of all search plans. Also, we consider $H$ be a set of positive integer numbers, where $H=\{1,2,3, \ldots\}$ and $L=\{1,2$, $3, \ldots, j\}$ be a finite subset of $H$. Also, we consider, $j \in L, i \in H$, where

$$
i=\left\{\begin{array}{cl}
1 & , \text { if } L \text { is empty set } \\
j+1 & , \text { if } L \text { is non-empty set }
\end{array}\right.
$$

On $L_{2}$ the two searchers $S_{3}$ and $S_{4}$ follow the search paths $\mathrm{k}$ and $z$, respectively to detect the target. The search path $\mathrm{k}$ of $\mathrm{S}_{3}$ is completely defined by a sequence $\left\{k_{\bar{l}}, \bar{l} \geq 0\right\}$ and the search path z of $S_{4}$ is completely defined by a sequence $\left\{z_{\bar{l}}, \bar{l} \geq 0\right\}$, where $\bar{l}$ is a nonnegative integer .let the search plan be represented by $\bar{\phi}=\left\{k_{\bar{i}}, z_{i}\right\} \in$ $\Phi_{2}$, where $\Phi_{2}$ is the set of all search plans. Also we consider $H$ be a set of positive integer numbers, where and $\overline{\mathbf{L}}=\{\{1,2,3, \ldots, \overline{\mathbf{j}}\}$ be a finite subset of $\mathrm{H}, \bar{l} \in H$. Also, we consider $\overline{\mathbf{j}} \in \mathbf{L}$, where :

$$
\bar{l}= \begin{cases}1 & , \text { if } \overline{\mathbf{L}} \text { is empty set } \\ \bar{j}+1 & \text {, if } \overline{\mathbf{L}} \text { is non -empty set }\end{cases}
$$

The probable search plans for the searchers $S_{1}$, $S_{2}, S_{3}$ and $S_{4}$ take the following cases according to the previous cases of the probable paths for the searchers $S_{1}, S_{2}, S_{3}$ and $S_{4}$ respectively.

Case(1), in this case we have the following search plan for $\mathrm{S}_{1}$ and $\mathrm{S}_{2}$ on $\mathrm{L}_{1}$

$\phi=\left\{\left(a_{i}, b_{i}\right)_{i \geq 0}: c<\ldots b_{i}<0<b_{j}<\ldots<b_{3}<b_{2}\right.$

$\left.<b_{1}<b_{0}=a_{0}<a_{1}<a_{2}<\ldots<d\right\}$

,where $d=\lim _{i \rightarrow \infty} a_{i}, \quad c=\lim _{i \rightarrow \infty} b_{i}$ and $\left|a_{i+1}-a_{i}\right|=\left|b_{i+1}-b_{i}\right|, i \geq 0$ 
and the following search plan for $S_{3}$ and $S_{4}$ on $L_{2}$

$\Phi=\left\{\left(k_{\bar{\imath}}, z_{\bar{l}}\right)_{\bar{i} \geq 0}: e<\ldots<z_{\bar{\imath}}<0<z_{j}<\ldots<z_{3}<z_{2}\right.$

$\left.<z_{1}<z_{0}=k_{0}<k_{1}<k_{2}<\ldots<g\right\}$

,where $\mathrm{g}=\lim _{\bar{i} \rightarrow \infty} \mathrm{k}_{\bar{\imath}}, \mathrm{e}=\lim _{\bar{\imath} \rightarrow \infty} \mathrm{Z}_{\bar{\imath}} \quad$ and $\left|\mathrm{k}_{\bar{\imath}+1}-\mathrm{k}_{\bar{\imath}}\right|=\left|\mathrm{z}_{\bar{\imath}+1}-\mathrm{z}_{\bar{\imath}}\right|, \bar{\imath} \geq 0$

Case(2), in this case we have the following search plan for $S_{1}$ and $S_{2}$ on $L_{1}$

$\phi=\left\{\left(a_{i}, b_{i}\right)_{i \geq 0}: c<\ldots b_{i}<0<b_{j}<\ldots<b_{3}<b_{2}\right.$ $\left.<b_{1}<b_{0}=a_{0}<a_{1}<a_{2}<\ldots<d\right\}$

and the following search plan for $S_{3}$ and $S_{4}$ on $L_{2}$

$\bar{\phi}=\left\{\left(k_{\bar{\imath}}, z_{i}\right)_{i \geq 0}: e<\ldots<z_{3}<z_{2}<z_{1}<z_{0}=k_{0}<k_{1}\right.$

$\left.<k_{2}<\ldots<k_{j}<0<k_{\bar{l}}<\ldots<g\right\}$

Case(3), in this case we have the following search plan for $\mathrm{S}_{1}$ and $\mathrm{S}_{2}$ on $\mathrm{L}_{1}$

$\phi=\left\{\left(a_{i}, b_{i}\right)_{i \geq 0}: c<\ldots<b_{3}<b_{2}<b_{1}<b_{0}=a_{0}\right.$ $\left.<a_{1}<a_{2}<\ldots<a_{j}<0<a_{i}<\ldots<d\right\}$

and the following search plan for $\mathrm{S}_{3}$ and $\mathrm{S}_{4}$ on $\mathrm{L}_{2}$

$\Phi=\left\{\left(k_{i}, z_{i}\right)_{i \geq 0}: e<\ldots<z_{i}<0<z_{j}<\ldots<z_{3}<\right.$ $\left.z_{2}<z_{1}<z_{0}=k_{0}<k_{1}<k_{2}<\ldots<g\right\}-$

Case(4), in this case we have the following search plan for $\mathrm{S}_{1}$ and $\mathrm{S}_{2}$ on $\mathrm{L}_{1}$

$\phi=\left\{\left(a_{i}, b_{i}\right)_{i \geq 0}: c<\ldots<b_{3}<b_{2}<b_{1}<b_{0}=\right.$ $\left.a_{0}<a_{1}<a_{2}<\ldots<a_{j}<0<a_{i}<\ldots<d\right\}$

and the following search plan forS $\mathrm{S}_{3}$ and $\mathrm{S}_{4}$ on $\mathrm{L}_{2}$

$\bar{\phi}=\left\{\left(k_{\bar{\imath}}, z_{i}\right)_{i \geq 0}: e<\ldots<z_{3}<z_{2}<z_{1}<z_{0}=k_{0}\right.$ $<k_{1}<k_{2}<\ldots<k_{j}<0<k_{i}<\ldots<g$ \}

Case(5), in this case we have the following search plan for $\mathrm{S}_{1}$ and $\mathrm{S}_{2}$ on $\mathrm{L}_{1}$

$\phi=\left\{\left(a_{i}, b_{i}\right)_{i \geq 0}: c<\ldots<b_{3}<b_{2}<b_{1}<b_{0}=a_{0}=\right.$ $\left.0<a_{1}<a_{2}<a_{3}<\ldots<d\right\}$

and the following search plan for $\mathrm{S}_{3}$ and $\mathrm{S}_{4}$ on $\mathrm{L}_{2}$ $\bar{\phi}=\left\{\left(k_{\bar{\imath}}, z_{i}\right)_{i \geq 0}: e<\ldots<z_{3}<z_{2}<z_{1}<z_{0}=k_{0}=\right.$ $0<k_{1}<k_{2}<k_{3}<\ldots<g$ \}

Case(6), in this case we have the following search plan for $\mathrm{S}_{1}$ and $\mathrm{S}_{2}$ on $\mathrm{L}_{1}$

$\phi=\left\{\left(a_{i}, b_{i}\right)_{i \geq 0}: c<\ldots b_{i}<0<b_{j}<\ldots<b_{3}<b_{2}\right.$ $\left.<b_{1}<b_{0}=a_{0}<a_{1}<a_{2}<\ldots .<d\right\}$

and the following search plan for $\mathrm{S}_{3}$ and $\mathrm{S}_{4}$ on $\mathrm{L}_{2}$

$\bar{\phi}=\left\{\left(k_{i}, z_{i}\right)_{i \geq 0}: e<\ldots<z_{3}<z_{2}<z_{1}<z_{0}=k_{0}=\right.$ $0<k_{1}<k_{2}<k_{3}<\ldots<g$ \}

Case(7), in this case we have the following search plan for $\mathrm{S}_{1}$ and $\mathrm{S}_{2}$ on $\mathrm{L}_{1}$

$\phi=\left\{\left(a_{i}, b_{i}\right)_{i \geq 0}: c<\ldots<b_{3}<b_{2}<b_{1}<b_{0}=\right.$ $\left.a_{0}<a_{1}<a_{2}<\ldots<a_{j}<0<a_{i}<\ldots<d\right\}$

and the following search plan for $\mathrm{S}_{3}$ and $\mathrm{S}_{4}$ on $\mathrm{L}_{2}$

$\bar{\phi}=\left\{\left(k_{\bar{i}}, z_{i}\right)_{i \geq 0}: e<\ldots<z_{3}<z_{2}<z_{1}<z_{0}=k_{0}=\right.$ $0<k_{1}<k_{2}<k_{3}<\ldots<g$ \}

Case(8), in this case we have the following search plan for $\mathrm{S}_{1}$ and $\mathrm{S}_{2}$ on $\mathrm{L}_{1}$ $\phi=\left\{\left(a_{i}, b_{i}\right)_{i \geq 0}: c<\ldots<b_{3}<b_{2}<b_{1}<b_{0}=a_{0}\right.$ $\left.=0<a_{1}<a_{2}<a_{3}<\ldots<\mathrm{d}\right\}$

and the following search plan for $\mathrm{S}_{3}$ and $\mathrm{S}_{4}$ on $\mathrm{L}_{2}$ $\Phi=\left\{\left(k_{\bar{\imath}}, z_{\bar{l}}\right)_{\bar{i} \geq 0}: e<\ldots<z_{3}<z_{2}<z_{1}<z_{0}=k_{0}<\right.$ $k_{1}<k_{2}<\ldots<k_{j}<0<k_{i}<\ldots<g$ \}

Case(9), in this case we have the following search plan for $\mathrm{S}_{1}$ and $\mathrm{S}_{2}$ on $\mathrm{L}_{1}$

$\phi=\left\{\left(a_{i}, b_{i}\right)_{i \geq 0}: c<\ldots<b_{3}<b_{2}<b_{1}<b_{0}=a_{0}=\right.$ $\left.0<a_{1}<a_{2}<a_{3}<\ldots<d\right\}$

and the following search plan for $\mathrm{S}_{3}$ and $\mathrm{S}_{4}$ on $\mathrm{L}_{2}$

$\bar{\Phi}=\left\{\left(k_{\bar{\imath}}, z_{i}\right)_{i \geq 0}: e \overline{<} \ldots<z_{\bar{i}}<0<z_{J}<\ldots<z_{3}<z\right.$ $\left.{ }_{2}<z_{1}<z_{0}=k_{0}<k_{1}<k_{2}<\ldots<g\right\}-$

The four searchers $S_{i}, i=1,2,3$ and 4 start together looking for the target from the intersection point of the two lines $L_{1}$ and $L_{2}$, where $\mathrm{a}_{0}=\mathrm{b}_{0}, \mathrm{k}_{0}=\mathrm{z}_{0}$. On $\mathrm{L}_{1}$ the searcher $\mathrm{S}_{1}$ goes from the intersection point to $\mathrm{a}_{1}$ and the searcher $\mathrm{S}_{2}$ goes from the intersection point to $b_{1}$ then they return to the intersection point. Also, on $\mathrm{L}_{2}$ the searcher $\mathrm{S}_{3}$ goes from the intersection point to $\mathrm{k}_{1}$ and the searcher $\mathrm{S}_{4}$ goes from the intersection point to $Z_{1}$ then they return to the intersection point. The two searchers $S_{1}$ and $S_{2}$ have the same distances on $\mathrm{L}_{1}$ and the other two searchers $\mathrm{S}_{3}$ and $\mathrm{S}_{4}$ have the same distances on $\mathrm{L}_{2}$ but differ from the distances of $S_{1}$ and $S_{2}$ on $L_{1}$ because the lost target has the two difference symmetric distributions on $L_{1}$ and $L_{2}$. The four searchers meet back at the intersection point but may be the first two searchers $S_{1}$ and $S_{2}$ meet back at the intersection point before the second two searchers $S_{3}$ and $S_{4}$ in this case the searchers $S_{1}$ and $S_{2}$ will be wait the other two searchers $S_{3}$ and $\mathrm{S}_{4}$ until they arrived to the intersection point on the other hand the two searchers $\mathrm{S}_{3}$ and $\mathrm{S}_{4}$ may be meet back at the intersection point before the second two searchers $S_{1}$ and $S_{2}$ in this case the searchers $S_{3}$ and $S_{4}$ will be wait the other two searchers $S_{1}$ and $S_{2}$ until they arrived to the intersection point. If they did not detect the target they start the search again from the intersection point to the right and the left and again they return to the intersection point and so on until one of them detect the target.

Let $\mathrm{V}_{\mathrm{i}}=1, \mathrm{i}=1,2,3,4$ and the search plan of the searchers represented by $\Phi=(\phi, \bar{\phi}) € \widetilde{\Phi}$, where $\widetilde{\Phi}$ is the set of all search plans. On $\mathrm{L}_{1}$ we assume that the probability of the position of the target at each point in $\{\mathrm{c}, \mathrm{d}\}$ can be calculated from a given distribution function $\mathrm{F}_{1}(\mathrm{x})$ with a density function $\mathrm{f}_{1}(\mathrm{x})$ which is symmetric about the intersection point. Also, on $\mathrm{L}_{2}$ the probability of the position of the target at each point in $\{\mathrm{e}, \mathrm{g}\}$ can be calculated from another distribution 
function $\mathrm{F}_{2}(\mathrm{y})$ with a density function $\mathrm{f}_{2}(\mathrm{y})$ which is symmetric about the intersection point. Let $\mid a_{i}$ $-\mathrm{a}_{\mathrm{i}-1}|=| \mathrm{b}_{\mathrm{i}}-\mathrm{b}_{\mathrm{i}-1} \mid$ on $\mathrm{L}_{1}$ are differ from $\left|\mathrm{k}_{\mathrm{i}}-\mathrm{k}_{\mathrm{i}-1}\right|=$ $\left|\mathrm{z}_{\mathrm{i}}-\mathrm{Z}_{\mathrm{i}-1}\right|$ on $\mathrm{L}_{2}, \mathrm{i} \geq 0$.

There is a known probability measure $V=V 1+V_{2}$ on $\{c, d\} \cup\{\mathrm{e}, \mathrm{g}\}$ which describes the position of the target,where $\mathrm{v} 1$ is the probability measure induced by the position of the target on $\{\mathrm{c}, \mathrm{d}\}$ .Also , v2 is the probability measure induced by the position of the target on $\{\mathrm{e}, \mathrm{g}\}$, and $\mathrm{v} 1\{\mathrm{c}, \mathrm{d}\}+$ $\mathrm{v} 2\{\mathrm{e}, \mathrm{g}\}=1$, where.

vl $\left(x_{1}, x_{2}\right)=F_{1}\left(x_{2}\right)-F_{1}\left(x_{1}\right)$.

and

$\mathrm{v} 2\left(\mathrm{y}_{1}, \mathrm{y}_{2}\right)=\mathrm{F}_{2}\left(\mathrm{y}_{2}\right)-\mathrm{F}_{2}\left(\mathrm{y}_{1}\right)$

Let $D_{i}, i=1,2$ be the time for the searcher $S_{i}, i$ $=1,2$ to return to the starting point if the other searcher has found the target. Also, let $\bar{D}_{i}, i=3$, 4 be the time for the searcher $S_{i}, i=3,4$ to return to the starting point if the other searcher has found the target and $\mathrm{D}(\Phi)$ be the time for the searchers to return to the starting point if one of them has found the target .

Remark 1: The waiting time between the searchers at the intersection point is out of the cost.

In the following theorem we assume that $\mathrm{D}_{1}=\mathrm{D}_{2}$ on the first line $\mathrm{L}_{1}$, and $\overline{\mathrm{D}}_{3}=\overline{\mathrm{D}}_{4}$ on the second line $\mathrm{L}_{2}$ according to the probability of the position of the lost target on the two lines.

We consider from now case (1).

Theorem 1 The expected value of the time for the searchers to return to the intersection point $\mathrm{a}_{0}$ $=\mathrm{b}_{0}, \mathrm{k}_{0}=\mathrm{z}_{0}$ if one of them has found the target is given by

$$
\begin{aligned}
E(D(\Phi))= & 2 \sum_{w=1}^{j}\left(a_{w}-a_{0}\right)\left[v_{1}(c, d)-v_{1}\left(b_{w-1}, a_{w-1}\right)\right] \\
& +2 \sum_{w=1}^{\infty}\left(a_{w}-a_{0}\right)\left[v_{1}(c, d)-v_{1}\left(b_{w-1}, a_{w-1}\right)\right] \\
& +2 \sum_{\bar{W}=1}^{i}\left(k_{\bar{w}}-k_{0}\right)\left[v_{2}(e, g)-v_{2}\left(\mathrm{z}_{\overline{\mathrm{w}}-1}, \mathrm{k}_{\overline{\mathrm{w}}-1}\right)\right] \\
& +2 \sum_{\overline{\mathrm{w}}=1}^{\infty}\left(\mathrm{k}_{\overline{\mathrm{w}}}-\mathrm{k}_{0}\right)\left[\mathrm{v}_{2}(\mathrm{e}, \mathrm{g})-\mathrm{v}_{2}\left(\mathrm{z}_{\overline{\mathrm{w}} 1}, \mathrm{k}_{\overline{\mathrm{w}} 1}\right)\right]
\end{aligned}
$$

$\underline{\text { Proof }}$

1)If the target is detected on $L_{1}$ we find : If the target lies in $\left.] \mathrm{a}_{0}, \mathrm{a}_{1}\right]$, then $\mathrm{D}_{2}=-2\left(\mathrm{~b}_{1}-\mathrm{b}_{0}\right)$,
If the target lies in $\left.] \mathrm{a}_{1}, \mathrm{a}_{2}\right]$, then

$\left.D_{2}=-2\left(b_{1}-b_{0}\right)+\left(b_{2}-b_{0}\right)\right]$,

If the target lies in $\left.] \mathrm{a}_{2}, \mathrm{a}_{3}\right]$, then

$\left.\left.D_{2}=-2\left(b_{1}-b_{0}\right)+\left(b_{2}-b_{0}\right)\right]+\left(b_{3}-b_{0}\right)\right]$,

If the target lies in $\left.] a_{j-1}, a_{j}\right]$, then

$\left.\left.D_{2}=-2\left(b_{1}-b_{0}\right)+\left(b_{2}-b_{0}\right)\right]+\left(b_{3}-b_{0}\right)\right]+\ldots+$

$\left.\left(b_{j-1}-b_{0}\right)+\left(b_{j}-b_{0}\right)\right]$,

If the target lies in $] \mathrm{a}_{\mathrm{i}}, \mathrm{a}_{\mathrm{j}}$, then

$\left.\left.D_{2}=-2\left(b_{1}-b_{0}\right)+\left(b_{2}-b_{0}\right)\right]+\left(b_{3}-b_{0}\right)\right]+\ldots+$

$\left.\left(b_{j-1}-b_{0}\right)+\left(b_{j}-b_{0}\right)+\left(b_{i}-b_{0}\right)\right]$,

If the target lies in $\left.] \mathrm{a}_{\mathrm{j}}, \mathrm{a}_{\mathrm{j}+1}\right]$, then

$\left.\left.D_{2}=-2\left(b_{1}-b_{0}\right)+\left(b_{2}-b_{0}\right)\right]+\left(b_{3}-b_{0}\right)\right]+\ldots+$

$\left.\left(b_{j-1}-b_{0}\right)+\left(b_{j}-b_{0}\right)+\left(b_{i}-b_{0}\right)+\left(b_{i+1}-b_{0}\right)\right]$.

and so on.

If the target lies in $\left[b_{1}, b_{0}[\right.$, then

$\mathrm{D}_{1}=2\left(\mathrm{a}_{1}-\mathrm{a}_{0}\right)$,

If the target lies in $\left[b_{2}, b_{1}[\right.$, then

$\left.D_{1}=2\left(a_{1}-a_{0}\right)+\left(a_{2}-a_{0}\right)\right]$,

If the target lies in $\left[b_{3}, b_{2}[\right.$, then

$\left.\left.D_{1}=2\left(a_{1}-a_{0}\right)+\left(a_{2}-a_{0}\right)\right]+\left(a_{3}-a_{0}\right)\right]$,

If the target lies in $\left[b_{j}, b_{j-1}[\right.$, then

$\left.\left.D_{1}=2\left(a_{1}-a_{0}\right)+\left(a_{2}-a_{0}\right)\right]+\left(a_{3}-a_{0}\right)\right]+\ldots+\left(a_{j-1}-\right.$

$\left.\left.a_{0}\right)+\left(a_{j}-a_{0}\right)\right]$,

If the target lies in $\left[b_{i}, b_{j}[\right.$, then

$\left.\left.D_{1}=2\left(a_{1}-a_{0}\right)+\left(a_{2}-a_{0}\right)\right]+\left(a_{3}-a_{0}\right)\right]+\ldots+\left(a_{j-1}-\right.$

$\left.\left.a_{0}\right)+\left(a_{j}-a_{0}\right)+\left(a_{i}-a_{0}\right)\right]$,

If the target lies in $\left[b_{i+1}, b_{i}[\right.$, then

$\left.\left.\mathrm{D}_{1}=2\left(\mathrm{a}_{1}-\mathrm{a}_{0}\right)+\left(\mathrm{a}_{2}-\mathrm{a}_{0}\right)\right]+\left(\mathrm{a}_{3}-\mathrm{a}_{0}\right)\right]+\ldots+\left(\mathrm{a}_{\mathrm{j}-1}-\right.$

$\left.\left.\mathrm{a}_{0}\right)+\left(\mathrm{a}_{\mathrm{j}}-\mathrm{a}_{0}\right)+\left(\mathrm{a}_{\mathrm{i}}-\mathrm{a}_{0}\right)+\left(\mathrm{a}_{\mathrm{i}+1}-\mathrm{a}_{0}\right)\right]$,

and so on.

2) If the target is detected on the second line $\mathrm{L}_{2}$ we find:

If the target lies in $\left.] \mathrm{k}_{0}, \mathrm{k}_{1}\right]$, then

$\overline{\mathrm{D}}_{4}=-2\left(\mathrm{z}_{1}-\mathrm{z}_{0}\right)$,

If the target lies in $] \mathrm{k}_{1}, \mathrm{k}_{2}$ ], then

$\overline{\mathrm{D}}_{4}=-2\left[\left(\mathrm{z}_{1}-\mathrm{z}_{0}\right)+\left(\mathrm{z}_{2}-\mathrm{z}_{0}\right)\right]$,

If the target lies in $] \mathrm{k}_{2}, \mathrm{k}_{3}$ ], then

$\overline{\mathrm{D}}_{4}=-2\left[\left(\mathrm{z}_{1}-\mathrm{z}_{0}\right)+\left(\mathrm{z}_{2}-\mathrm{z}_{0}\right)+\left(\mathrm{z}_{3}-\mathrm{z}_{0}\right)\right]$,

If the target lies in ] k $]_{-1}, \mathrm{k}$ ] ], then

$\overline{\mathrm{D}}_{4}=-2\left[\left(\mathrm{z}_{1}-\mathrm{z}_{0}\right)+\left(\mathrm{z}_{2}-\mathrm{z}_{0}\right)+\left(\mathrm{z}_{3}-\mathrm{z}_{0}\right)+\ldots+\left(\mathrm{z}_{-1}-1-\right.\right.$

$\left.\left.\mathrm{z}_{0}\right)+\left(\mathrm{z}_{\mathbf{l}}-\mathrm{z}_{0}\right)\right]$,

If the target lies in ] kı, ki], then

$\overline{\mathrm{D}}_{4}=-2\left[\left(\mathrm{z}_{1}-\mathrm{z}_{0}\right)+\left(\mathrm{z}_{2}-\mathrm{z}_{0}\right)+\left(\mathrm{z}_{3}-\mathrm{z}\right)+\ldots+\left(\mathrm{z}_{-1}-\right.\right.$

$\left.\left.\mathrm{z}_{0}\right)+\left(\mathrm{z}-\mathrm{z}_{0}\right)+\left(\mathrm{z} \overline{\mathrm{l}}-\mathrm{z}_{0}\right)\right]$,

If the target lies in ] $\mathrm{k}_{\mathbf{i}}, \mathrm{k}_{\mathbf{i}+1}$ ], then

$\overline{\mathrm{D}}_{4}=-2\left[\left(\mathrm{z}_{1}-\mathrm{z}_{0}\right)+\left(\mathrm{z}_{2}-\mathrm{z}_{0}\right)+\left(\mathrm{z}_{3}-\mathrm{z}_{0}\right)+\ldots+\left(\mathrm{z}_{-1}-\right.\right.$

$\left.\left.\mathrm{z}_{0}\right)+\left(\mathrm{z} \mathbf{l}-\mathrm{z}_{0}\right)+\left(\mathrm{z} \mathbf{i}-\mathrm{z}_{0}\right)+\left(\mathrm{z} \mathfrak{i}_{+1}-\mathrm{z}_{0}\right)\right]$

and so on.

If the target lies in $\left[z_{0}, z_{1}[\right.$, then

$\overline{\mathrm{D}}_{3}=2\left(\mathrm{k}_{1}-\mathrm{k}_{0}\right)$,

If the target lies in $\left[z_{2}, z_{1}[\right.$, then

$\left.\overline{\mathrm{D}}_{3}=2\left(\mathrm{k}_{1}-\mathrm{k}_{0}\right)+\left(\mathrm{k}_{2}-\mathrm{k}_{0}\right)\right]$,

If the target lies in $\left[z_{3}, z_{2}[\right.$, then 
$\left.\left.\overline{\mathrm{D}}_{3}=2\left(\mathrm{k}_{1}-\mathrm{k}_{0}\right)+\left(\mathrm{k}_{2}-\mathrm{k}_{0}\right)\right]+\left(\mathrm{k}_{3}-\mathrm{k}_{0}\right)\right]$,

If the target lies in [z;-1,z! [, then

$\left.\left.\overline{\mathbf{D}}_{3}=2\left(\mathrm{k}_{1}-\mathrm{k}_{0}\right)+\left(\mathrm{k}_{2}-\mathrm{k}_{0}\right)\right]+\left(\mathrm{k}_{3}-\mathrm{k}_{0}\right)\right]+\ldots+\left(\mathrm{k}_{\mathrm{r}-1}-\right.$

$\left.\left.\mathrm{k}_{0}\right)+\left(\mathrm{k}-\mathrm{k}_{0}\right)\right]$,

If the target lies in $\left[\mathrm{Z}_{\mathbf{i}}, \mathrm{Z}_{\mathrm{i}}[\right.$, then

$\left.\left.\overline{\mathrm{D}}_{3}=2\left(\mathrm{k}_{1}-\mathrm{k}_{0}\right)+\left(\mathrm{k}_{2}-\mathrm{k}_{0}\right)\right]+\left(\mathrm{k}_{3}-\mathrm{k}_{0}\right)\right]+\ldots+\left(\mathrm{k}_{-1}-\right.$

$\left.\left.\mathrm{k}_{0}\right)+\left(\mathrm{k}_{\mathfrak{l}}-\mathrm{k}_{0}\right)+\left(\mathrm{k}^{\mathrm{i}}-\mathrm{k}_{0}\right)\right]$,

If the target lies in $\left[\mathrm{Z}_{\mathbf{l}}, \mathrm{Z}_{\mathbf{l}}+1[\right.$, then

$\left.\left.\overline{\mathrm{D}}_{3}=2\left(\mathrm{k}_{1}-\mathrm{k}_{0}\right)+\left(\mathrm{k}_{2}-\mathrm{k}_{0}\right)\right]+\left(\mathrm{k}_{3}-\mathrm{k}_{0}\right)\right]+\ldots+\left(\mathrm{k} \mathrm{k}_{1}-\right.$

$\left.\left.\mathrm{k}_{0}\right)+\left(\mathrm{k}_{\mathrm{j}}-\mathrm{k}_{0}\right)+\left(\mathrm{k}_{\mathbf{j}}-\mathrm{k}_{0}\right)++\left(\mathrm{k}_{\mathbf{j}+1}-\mathrm{k}_{0}\right)\right]$,

And so on, then we can calculate $\mathrm{E}[\mathrm{D}(\Phi)]$ as

follows:

$\mathrm{E}[\mathrm{D}(\Phi)]=2\left(\mathrm{a}_{1}-\mathrm{a}_{0}\left[\mathrm{v}_{1}\left(\mathrm{a}_{0}, \mathrm{a}_{1}\right)+\mathrm{v}_{1}\left(\mathrm{a}_{1}, \mathrm{a}_{2}\right)+\mathrm{v}_{1}\left(\mathrm{a}_{2}\right.\right.\right.$,

$\left.a_{3}\right)+\ldots+v_{1}\left(a_{j}, a_{i}\right)+v_{1}\left(a_{i}, a_{i+1}\right)+\ldots+v_{1}\left(b_{1}, b_{0}\right)+$

$\mathrm{v}_{1}\left(\mathrm{~b}_{2}, \mathrm{~b}_{1}\right)+\mathrm{v}_{1}\left(\mathrm{~b}_{3}, \mathrm{~b}_{2}\right)+\ldots+\mathrm{v}_{1}\left(\mathrm{~b}_{\mathrm{i}}, \mathrm{b}_{\mathrm{j}}\right)+\mathrm{v}_{1}\left(\mathrm{~b}_{\mathrm{i}+1}, \mathrm{~b}_{\mathrm{i}}\right)$

$+\ldots]$

$+2\left(a_{2}-a_{0}\right)\left[v_{1}\left(a_{1}, a_{2}\right)+v_{1}\left(a_{2}, a_{3}\right)+\ldots\right.$

$+\mathrm{v}_{1}\left(\mathrm{a}_{\mathrm{j}}, \mathrm{a}_{\mathrm{i}}\right)+\mathrm{v}_{1}\left(\mathrm{a}_{\mathrm{i}}, \mathrm{a}_{\mathrm{i}+1}\right)+\ldots+\mathrm{v}_{1}\left(\mathrm{~b}_{2}, \mathrm{~b}_{1}\right)+\mathrm{v}_{1}\left(\mathrm{~b}_{3}\right.$, $\left.\left.b_{2}\right)+\ldots+v_{1}\left(b_{i}, b_{j}\right)+v_{1}\left(b_{i+1}, b_{i}\right)+v_{1}\left(b_{i+2}, b_{i+1}\right)\right]$

$\left.+2\left(a_{3}-a_{0}\right)\right)\left[v_{1}\left(a_{2}, a_{3}\right)+\ldots\right.$

$+\mathrm{v}_{1}\left(\mathrm{a}_{\mathrm{j}}, \mathrm{a}_{\mathrm{i}}\right)+\mathrm{v}_{1}\left(\mathrm{a}_{\mathrm{i}}, \mathrm{a}_{\mathrm{i}+1}\right)+\ldots+\mathrm{v}_{1}\left(\mathrm{~b}_{3}, \mathrm{~b}_{2}\right)+\ldots+$

$\left.\mathrm{v}_{1}\left(\mathrm{~b}_{\mathrm{i}}, \mathrm{b}_{\mathrm{j}}\right)+\mathrm{v}_{1}\left(\mathrm{~b}_{\mathrm{i}+1}, \mathrm{~b}_{\mathrm{i}}\right)+\mathrm{v}_{1}\left(\mathrm{~b}_{\mathrm{i}+2}, \mathrm{~b}_{\mathrm{i}+1}\right)\right]+\ldots$

$+2\left(\mathrm{k}_{1}-\mathrm{a}_{0}\right)\left[\mathrm{v}_{2}\left(\mathrm{k}_{0}, \mathrm{k}_{1}\right)+\mathrm{v}_{2}\left(\mathrm{k}_{1}, \mathrm{k}_{2}\right)+\mathrm{v}_{2}\left(\mathrm{k}_{2}, \mathrm{k}_{3}\right)+\right.$

$\ldots+\mathrm{v}_{2}\left(\mathrm{k}_{\mathfrak{l}}, \mathrm{k}_{\overline{\mathrm{l}}}\right)+\mathrm{v}_{2}\left(\mathrm{k}_{\overline{\mathrm{l}}}, \mathrm{k}_{\overline{\mathrm{l}}+1}\right)+\ldots+\mathrm{v}_{2}\left(\mathrm{z}_{1}, \mathrm{z}_{0}\right)+$

$\mathrm{v}_{2}\left(\mathrm{z}_{2}, \mathrm{z}_{1}\right)+\mathrm{v}_{2}\left(\mathrm{z}_{3}, \mathrm{z}_{2}\right)+\ldots+\mathrm{v}_{2}\left(\mathrm{z}_{\mathbf{i}+1}, \mathrm{z}_{\mathrm{j}}\right)+\mathrm{v}_{2}(\mathrm{z} \overline{\mathbf{l}}+2$,

$\mathrm{Zj}+1)+\ldots]$

$+2\left(\mathrm{k}_{2}-\mathrm{a}_{0}\right)\left[\mathrm{v}_{2}\left(\mathrm{k}_{1}, \mathrm{k}_{2}\right)+\mathrm{v}_{2}\left(\mathrm{k}_{2}, \mathrm{k}_{3}\right)+\ldots+\mathrm{v}_{2}\left(\mathrm{k}_{\mathrm{l}-1}, \mathrm{k}_{1}\right)\right.$

$+\mathrm{v}_{2}\left(\mathrm{k}_{\mathfrak{l}}, \mathrm{k}_{\mathrm{i}}\right)+\mathrm{v}_{2}\left(\mathrm{k}_{\mathbf{l}}, \mathrm{k}_{\mathbf{j}+1}\right)+\ldots+\mathrm{v}_{2}\left(\mathrm{z}_{2}, \mathrm{z}_{1}\right)+\mathrm{v}_{2}\left(\mathrm{z}_{3}\right.$,

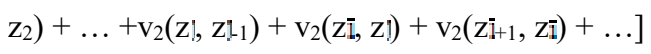

$+2\left(\mathrm{k}_{3}-\mathrm{a}_{0}\right)\left[\mathrm{v}_{2}\left(\mathrm{k}_{2}, \mathrm{k}_{3}\right)\right.$

$+\ldots+\mathrm{v}_{2}\left(\mathrm{k}_{1}, \mathrm{k} \mathfrak{i}\right)+\mathrm{v}_{2}\left(\mathrm{k}_{i}, \mathrm{ki}\right)+\mathrm{v}_{2}\left(\mathrm{k}_{\mathrm{i}}, \mathrm{k} \mathrm{i}_{\mathbf{1}+1}\right)+\ldots+\mathrm{v}_{2}\left(\mathrm{z}_{3}, \mathrm{z}_{2}\right)$

$\left.+\ldots+\mathrm{v}_{2}(\mathrm{Z}, \mathrm{Z}-1)+\mathrm{v}_{2}\left(\mathrm{Zi}_{\mathrm{i}}, \mathrm{Z}\right)+\mathrm{v}_{2}\left(\mathrm{Z}_{\mathrm{i}+1}, \mathrm{Zi}\right)+\ldots\right]+\ldots$

$=2\left(\mathrm{a}_{1}-\mathrm{a}_{0}\right)\left[\mathrm{v}_{1}(\mathrm{c}, \mathrm{d})\right]+2\left(\mathrm{a}_{2}-\mathrm{a}_{0}\right)\left[\mathrm{v}_{1}(\mathrm{c}, \mathrm{d})-\right.$

$\left.\mathrm{v}_{1}\left(\mathrm{~b}_{1}, \mathrm{a}_{1}\right)\right]+2\left(\mathrm{a}_{3}-\mathrm{a}_{0}\right)\left[\mathrm{v}_{1}(\mathrm{c}, \mathrm{d})-\mathrm{v}_{1}\left(\mathrm{~b}_{2}, \mathrm{a}_{2}\right)\right]+\ldots$

$+2\left(\mathrm{k}_{1}-\mathrm{a}_{0}\right)\left[\mathrm{v}_{2}(\mathrm{e}, \mathrm{g})\right]+2\left(\mathrm{k}_{2}-\mathrm{a}_{0}\right)\left[\mathrm{v}_{2}(\mathrm{e}, \mathrm{g})-\right.$

$\left.\mathrm{v}_{2}\left(\mathrm{z}_{1}, \mathrm{k}_{1}\right)\right]+2\left(\mathrm{k}_{3}-\mathrm{a}_{0}\right)\left[\mathrm{v}_{2}(\mathrm{e}, \mathrm{g})-\mathrm{v}_{2}\left(\mathrm{z}_{2}, \mathrm{k}_{2}\right)\right]+\ldots$

$=2 \sum_{w=1}^{j}\left(a_{w}-a_{0}\right)\left[v_{1}(c, d)-v_{1}\left(b_{w-1}, a_{w-1}\right)\right]$

$+2 \sum_{w=1}^{\infty}\left(a_{w}-a_{0}\right)\left[v_{1}(c, d)-v_{1}\left(b_{w-1}, a_{w-1}\right)\right]$
$+2 \sum_{\mathrm{W}=1}^{j}\left(\mathrm{k}_{\overline{\mathrm{W}}}-\mathrm{k}_{3}\right)\left[\mathrm{v}_{2}(\mathrm{e}, \mathrm{g})-\mathrm{v}_{2}\left(\mathrm{z}_{\overline{\mathrm{W}}-1}, \mathrm{k}_{\overline{\mathrm{W}}-1}\right)\right]$

$+2 \sum_{\bar{w}=\overline{\mathrm{i}}}^{\infty}\left(\mathrm{k}_{\overline{\mathrm{w}}}-\mathrm{k}_{0}\right)\left[\mathrm{v}_{2}(\mathrm{e}, \mathrm{g})-\mathrm{v}_{2}\left(\mathrm{z}_{\overline{\mathrm{w}}-1}, \mathrm{k}_{\overline{\mathrm{w}}-\mathrm{I}}\right)\right]$

$, 1 \leq \overline{\mathbf{j}}<\overline{\mathbf{i}}, \mathbf{j}=\mathbf{j}+1$

Definition 1 : let $\Phi^{*} \in \Phi$ be a search plan, then $\Phi^{*}$ is an optimal search plan if :

$\mathrm{E}\left[\mathrm{D}\left(\Phi^{*}\right)\right]=\inf \{\mathrm{E}[\mathrm{D}(\Phi)], \Phi \in \Phi\}$,

Where $\Phi$ is the set of all search plans.

Theorem 2 : let $\mathrm{F}_{1}(x)$ be a continuous distribution with a density function $\mathrm{f}_{1}(x)$ and $\mathrm{f}_{2}(y)$ be $a$ continuous distribution with a density function $\mathrm{f}_{2}(y)$.if $\Phi=(\phi, \Phi) \in \Phi^{*}$ is an optimal search plan, then :

$a_{i+1}=\frac{\left[v_{1}(c, d)-v_{1}\left(b_{j}, a_{j}\right)\right]}{f_{1}\left(a_{j}\right)}+a_{0}$

$, 1 \leq \mathrm{j}<\mathrm{i}, \mathrm{i}=\mathrm{j}+1$

$\mathrm{k}_{\mathrm{i}+1}=\frac{\left[\mathrm{v}_{2}\left(\mathrm{e}_{\mathrm{g}} \mathrm{g}\right)-\mathrm{v}_{\mathrm{2}}(\mathrm{z}-\mathrm{k}-\mathrm{k})\right]}{\mathrm{f}_{\mathrm{z}}\left(\mathrm{k}_{\mathrm{i}}\right)}+\mathrm{k}_{0}$

$, 1 \leq \mathbf{j}<\overline{\mathbf{i}}, \overline{\mathbf{j}}=\mathbf{j}+1$

Proof: we have from [2.1]

$E[D(\phi)]=2 \sum_{w=1}^{j}\left(a_{w}-a_{0}\right)\left[v_{1}(c, d)-v_{1}\left(b_{w-1}, a_{w-1}\right)\right]+2 \sum_{w=1}^{\infty}\left(a_{w}-a_{0}\right)\left[v_{1}(c, d)\right.$ $\left.-v_{1}\left(b_{w-1}, a_{w-1}\right)\right]$

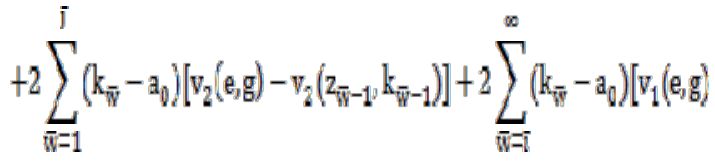
$\left.-v_{2}\left(z_{\bar{w}-1}, k_{\overline{\mathrm{w}}-1}\right)\right]$ 


$$
=2\left[\begin{array}{c}
\left(a_{1}-a_{0}\right)\left[v_{1}\left(c_{1} d\right)\right]+\left(a_{2}-a_{0}\right)\left[v_{1}(c, d)-v_{1}\left(b_{1}, a_{1}\right)\right] \\
+\left(a_{3}-a_{0}\right)\left[v_{1}(c, d)-v_{1}\left(b_{2}, a_{2}\right)\right]+\cdots \\
+\left(a_{j}-a_{0}\right)\left[v_{1}(c, d)-v_{1}\left(b_{j-1}, a_{j-1}\right)\right] \\
+\left(a_{j}-a_{0}\right)\left[v_{1}(c, d)-v_{1}\left(b_{j}, a_{j}\right)\right] \\
+\left(a_{j+1}-a_{0}\right)\left[v_{1}(c, d)-v_{1}\left(b_{i}, a_{i}\right)\right]+\cdots
\end{array}\right] \quad \text { Also, }
$$

Thus,

$$
+2\left[\begin{array}{c}
\left(k_{1}-a_{0}\right)\left[v_{2}(e, g)\right]+\left(k_{2}-a_{0}\right)\left[v_{2}(e, g)-v_{2}\left(z_{1}, k_{1}\right)\right] \\
+\left(k_{3}-a_{0}\right)\left[v_{2}(e, g)-v_{2}\left(z_{2}, k_{2}\right)\right]+\cdots \\
+\left(k_{j}-a_{0}\right)\left[v_{2}\left(e_{r} g\right)-v_{2}\left(z_{j-1}, k_{j-1}\right)\right] \\
+\left(k_{j}-a_{0}\right)\left[v_{2}(e, g)-v_{2}\left(z_{j}, k_{j}\right)\right] \\
+\left(k_{i+1}-a_{0}\right)\left[v_{2}(e, g)-v_{2}\left(z_{i}, k_{i}\right)\right]+\cdots
\end{array}\right]
$$

\section{Hence,}

$\frac{\partial \mathrm{E}[\mathrm{D}(\Phi)]}{\partial \mathrm{a}_{1}}=2\left[\mathrm{v}_{1}(\mathrm{c}, \mathrm{d})-\left(\mathrm{a}_{2}-\mathrm{a}_{0}\right) \mathrm{f}_{1}\left(\mathrm{a}_{1}\right)\right]=0$

Thus,

$$
a_{2}=\frac{v_{1}(c, d)}{f_{1}\left(a_{1}\right)}+a_{0}
$$

Also,

$$
\frac{\partial \mathrm{E}[\mathrm{D}(\Phi)]}{\partial \mathrm{a}_{2}}=2\left[\mathrm{v}_{1}(\mathrm{c}, \mathrm{d})-\mathrm{v}_{1}\left(\mathrm{~b}_{1}, \mathrm{a}_{1}\right)-\left(\mathrm{a}_{3}-\mathrm{a}_{0}\right) \mathrm{f}_{1}\left(\mathrm{a}_{2}\right)\right]=0
$$

Thus,

$a_{3}=\frac{\left[v_{1}(c, d)-v_{1}\left(b_{1}, a_{1}\right)\right]}{f_{1}\left(a_{2}\right)}+a_{0}$

\section{And so on, then:}

$\frac{\partial E[D(\Phi)]}{\partial a_{j-1}}=2\left[v_{1}(c, d)-v_{1}\left(b_{j-2}, a_{j-2}\right)-\left(a_{j}-a_{0}\right) f_{1}\left(a_{j-1}\right)\right]=0$

Thus,

$$
a_{j}=\frac{\left[v_{1}(c, d)-v_{1}\left(b_{j-2}, a_{j-2}\right)\right]}{f_{1}\left(a_{j-1}\right)}+a_{v}, 1 \leq j<i, i=j+1
$$

$a_{i}=\frac{\left[v_{1}(c, d)-v_{1}\left(b_{j-1}, a_{j-1}\right)\right]}{f_{1}\left(a_{j}\right)}+a_{0}, 1 \leq j<i, i=j+1$

Hence,

$a_{i+1}=\frac{\left[v_{1}(c, d)-v_{1}\left(b_{j}, a_{j}\right)\right]}{f_{1}\left(a_{i}\right)}+a_{0}, 1 \leq j<i, i=j+1$

By a similar way we can prove (2.3).

\section{Theorem 3:}

If $\Phi=(\phi, \bar{\phi})) \in \Phi$ is an optimal search plan, then

$\mathrm{f}_{1}\left(\mathrm{a}_{\mathrm{i}}\right)<\mathrm{f}_{1}\left(\mathrm{a}_{\mathrm{j}}\right)$ and $\mathrm{f}_{1}\left(\mathrm{~b}_{\mathrm{i}}\right)<\mathrm{f}_{1}\left(\mathrm{~b}_{\mathrm{j}}\right)$ on the first line $\mathrm{L}_{1}$

$\forall 1 \leq \mathrm{j}<\mathrm{i}, \mathrm{i}=\mathrm{j}+1$

Also,

$\mathrm{f}_{2}\left(\mathrm{k}_{\mathrm{i}}\right)<\mathrm{f}_{2}\left(\mathrm{k}_{\mathrm{i}}\right)$ and $\mathrm{f}_{2}(\mathrm{z} \mathrm{i})<\mathrm{f}_{2}\left(\mathrm{z}_{\mathrm{j}}\right)$. on the second line

$\mathrm{L}_{2} \forall 1 \leq \overline{\mathrm{j}}<\overline{\mathrm{j}}, \mathbf{\mathrm { i }}=\mathbf{j}+1$

Proof : We have from (2.2)and further from the definition of the search plan

$\mathrm{f}_{1}\left(\mathrm{a}_{\mathrm{i}}\right)=\frac{\mathrm{v}_{1}(\mathrm{c}, \mathrm{d})-\mathrm{v}_{1}\left(\mathrm{~b}_{\mathrm{j}}, \mathrm{a}_{\mathrm{j}}\right)}{\mathrm{a}_{\mathrm{j}+1}-\mathrm{a}_{0}}, 1 \leq \mathrm{j}<i, i=j+1$
$\mathrm{f}_{1}\left(\mathrm{a}_{2}\right)=\frac{\mathrm{v}_{1}(\mathrm{c}, \mathrm{d})-\mathrm{v}_{1}\left(\mathrm{~b}_{1}, \mathrm{a}_{1}\right)}{\mathrm{a}_{3}-\mathrm{a}_{0}}$

And

$\mathrm{f}_{1}\left(\mathrm{a}_{1}\right)=\frac{\mathrm{v}_{1}(\mathrm{c}, \mathrm{d})}{\mathrm{a}_{2}-\mathrm{a}_{0}}$

But

$\mathrm{v}_{1}(\mathrm{c}, \mathrm{d})>\mathrm{v}_{1}(\mathrm{c}, \mathrm{d})-\mathrm{v}_{1}\left(\mathrm{~b}_{1}, \mathrm{a}_{1}\right)>\mathrm{v}_{1}(\mathrm{c}, \mathrm{d})-\mathrm{v}_{1}\left(\mathrm{~b}_{2}, \mathrm{a}_{2}\right)$

$>v_{1}(c, d)-v_{1}\left(b_{j}, a_{j}\right), 1 \leq j<i,=j+1$

And

$\mathrm{a}_{2}-\mathrm{a}_{0}<\mathrm{a}_{3}-\mathrm{a}_{0}<\mathrm{a}_{\mathrm{j}+1}-\mathrm{a}_{0}$

Hence, 
$\frac{v_{1}(c, d)}{a_{2}-a_{0}}>\frac{v_{1}(c, d)-v_{1}\left(b_{1}, a_{1}\right)}{a_{3}-a_{0}}>\frac{v_{1}(c, d)-v_{1}\left(b_{j}, a_{j}\right)}{a_{i+1}-a_{0}}$

$a_{i+1}=\frac{\left[v_{1}(c, d)-v_{1}\left(b_{i-1}, a_{i-1}\right)\right]}{f_{1}\left(a_{i}\right)} \quad, i \geq 1$

Thus,

$f_{1}\left(a_{1}\right)>f_{1}\left(a_{2}\right)>f_{1}\left(a_{j}\right), j \geq 1$,

Then

$\mathrm{f}_{1}\left(\mathrm{a}_{\mathrm{i}}\right)<\mathrm{f}_{1}\left(\mathrm{a}_{\mathrm{j}}\right) \forall \mathrm{l} \leq \mathrm{j}<\mathrm{I}, \mathrm{I}=\mathrm{j}+1$

by similar way we can prove $\mathrm{f}_{1}\left(\mathrm{~b}_{\mathrm{i}}\right)<\mathrm{f}_{1}\left(\mathrm{~b}_{\mathrm{j}}\right)$ and

\section{Special cases:}

\section{Case(i)}

In case (1) if the target is located according to a known symmetric distribution on one of two intersected lines $\mathrm{L}_{1}$ and $\mathrm{L}_{2}$, where the distribution of the lost target is the same on the first line $\mathrm{L}_{1}$ and on the second line $\mathrm{L}_{2}$, then the expected value of the time of finding the lost target is :

$$
\begin{aligned}
& E[D(\Phi)]=2 \sum_{w=1}^{j}\left(a_{w}-a_{0}\right)\left[1-2 v_{1}\left(b_{w-1}, a_{w-1}\right)\right] \\
& \mid 2 \sum_{w=1}^{\infty}\left(a_{w} \quad a_{0}\right)\left[\begin{array}{ll}
1 & \left.2 v_{1}\left(b_{w-1}, a_{w-1}\right)\right]
\end{array}\right. \\
& a_{i+1}=\frac{\left[1-2 v_{1}\left(b_{i-1}, a_{i-1}\right)\right.}{f\left(a_{i}\right)}+a_{0}, 1 \leq j<l, l=j+1 \\
& k_{i+1}=\frac{\left[1-2 v_{2}\left(z_{i-1}, k_{i-1}\right)\right]}{f\left(k_{i}\right)}+k_{0}, 1 \leq \bar{j}<\bar{i}, \bar{l}=\bar{j}+1
\end{aligned}
$$

\section{Case (ii)}

In case (1) if the point of intersection of the two lines is the origin, where

$\mathrm{a}_{U}=\mathrm{b}_{U}=\mathrm{k}_{U}=\mathrm{z}_{U}=0$, then the expected

value of the time of finding the lost target is given by :

$\mathrm{E}[\mathrm{D}(\Phi)]=2 \sum_{\mathrm{w}=1}^{\infty} \mathrm{a}_{\mathrm{w}}\left[\mathrm{v}_{1}\left(c_{,} \mathrm{d}\right)-\mathrm{v}_{1}\left(\mathrm{~b}_{\mathrm{w}-1}, \mathrm{a}_{\mathrm{w}-1}\right)\right]$

$+2 \sum_{\bar{w}=1}^{\infty} k_{\bar{w}}\left[v_{2}(e, g)-v_{2}\left(z_{\bar{w}-1}, k_{\bar{w}-1}\right)\right]$

Also,

\section{Case (iii)}

In case $(\boldsymbol{i})$ if the target is located according to a known symmetric distribution on one of two intersected lines $\mathrm{L}_{1}$ and $\mathrm{L}_{2}$, where the distribution of the lost target is the same on the first line $L_{1}$ and on the second line $\mathrm{L}_{2}$, and the point of intersection of the two lines is the origin, then the expected value of the time of finding the lost target is given by the following :

$\mathrm{E}[\mathrm{D}(\Phi)]=2 \sum_{\mathrm{w}=1}^{\mathrm{j}} \mathrm{a}_{\mathrm{w}}\left[1-2 \mathrm{v}_{2}\left(\mathrm{~b}_{\mathrm{w}-1}, \mathrm{a}_{\mathrm{w}-1}\right)\right]$

$+2 \sum_{w=1}^{\infty} a_{w}\left[1-2 v_{1}\left(b_{w-1}, a_{w-1}\right)\right]$

Also,

$a_{i+1}=\frac{\left[1-2 v_{1}\left(b_{j-1}, a_{j-1}\right)\right]}{f\left(a_{i}\right)}, 1 \leq j<i, i=j+1$

$k_{i+1}=\frac{\left[1-2 v_{2}\left(z_{i-1 i}, k_{i-1}\right)\right]}{f\left(k_{i}\right)}, 1 \leq \bar{j}<\bar{i}, \overline{1}=\bar{j}+1$

\section{Case (iv)}

In case (i) if the target is located according to a known symmetric distribution on one of two intersected lines $\mathrm{L}_{1}$ and $\mathrm{L}_{2}$, where the distribution of the lost target is the same on the first line $\mathrm{L}_{1}$ and on the second line $L_{2}$, then $v_{1}=v_{2}$ and $\mathrm{f}_{1}(\mathrm{x})=\mathrm{f}_{2}(\mathrm{y})$ when $\mathrm{c}=\mathrm{e}$ and $\mathrm{d}=\mathrm{g}$ we find :

$\int_{0}^{\mathrm{d}} \mathrm{f}_{1}(\mathrm{x}) \mathrm{dx}=\int_{0}^{\mathrm{E}} \mathrm{f}_{2}(\mathrm{y}) \mathrm{dy}=\frac{1}{2}$ 
But if the target is located according to a known symmetric distribution on one of two intersected lines $\mathrm{L}_{1}$ and $\mathrm{L}_{2}$, where the distribution of the lost target is the same on the first line $\mathrm{L}_{1}$ and on the second line $\mathrm{L}_{2}$ but $\mathrm{c} \neq \mathrm{e}$ and $\mathrm{d} \neq \mathrm{g}$ we find : $\int_{c}^{d} f_{1}(x) d x \neq \int_{0}^{g} f_{2}(y) d y$

Case (v)

In case (i) if $v_{2}(e, g)=0$, then we can get the same result of [10].

\section{Example 1}

If $\mathrm{X}$ has the density function

$\mathrm{f}_{1}(\mathrm{x})=|\mathrm{x}|,-1<-\sqrt{\frac{1}{2}} \leq \mathrm{x} \leq \sqrt{\frac{1}{2}}<1$

,where $\mathrm{x}$ representing the position of the located target on the first line $\mathrm{L}_{1}$,

$c=-\sqrt{\frac{1}{2}}$ and $d=\sqrt{\frac{1}{2}}$

and $y$ has the density function

$\mathrm{f}_{2}(\mathrm{y})=|\mathrm{y}|,-1<-\sqrt{\frac{1}{2}} \leq \mathrm{y} \leq \sqrt{\frac{1}{2}}<1$

,where $y$ representing the position of the located target on the second line $\mathrm{L}_{2}$,

$g=-\sqrt{\frac{1}{2}}$ and $\mathrm{e}=\sqrt{\frac{1}{2^{3}}}$

and the two lines $L_{1}$ and $L_{2}$ are intrested in the origin.

Then the optimal search plan $\Phi^{*}=\left(\emptyset, \emptyset^{*}\right)$

consists of $\quad \ell=\left\{-\sqrt{\frac{1}{2}}, 0, \sqrt{\frac{1}{2}}\right\} \quad$ and

$\bar{\emptyset}^{*}=\left\{-\sqrt{\frac{1}{2}}, 0, \sqrt{\frac{1}{2}}\right\}$.

\section{Proof}

Let the optimal search plan $\Phi$ contains of

$\emptyset=\left\{-\sqrt{\frac{1}{2}},-a_{1}, 0, a_{1}, \sqrt{\frac{1}{2}}\right\}$ and

$\overline{\phi^{*}}=\left\{-\sqrt{\frac{1}{2}},-\mathrm{k}_{1}, 0, \mathrm{k}_{1}, \sqrt{\frac{1}{2}}\right\}$
But

$f_{1}\left(a_{1}\right)<f_{1}\left(\sqrt{1} \frac{1}{2}\right)$ and $f_{2}\left(k_{1}\right)<f_{2}\left(\sqrt{1} \frac{1}{2}\right)$

which contracted relation (2.4) and (2.5). Then

$\mathrm{a}_{1}=\mathrm{k}_{1}=\sqrt{\frac{1}{2}}$

Example 2

If $\mathrm{X}$ is a continuous random variable that has a uniform distribution with a probability density function

$f_{1}(x)=\frac{1}{b-a},-12<-3 \leq x \leq 3<12$

,where $\mathrm{x}$ representing the position of the located target on the first line $L_{1}, c=-3$ and $d=$ 3 ,

And $\mathrm{Y}$ be a continuous random variable has a triangular distribution with a probability density function

$\mathrm{f}_{2}(\mathrm{y})=\frac{1}{4}-\frac{1}{16}|\mathrm{y}|,-4<-2 \leq \mathrm{y} \leq 2<4$

,where $y$ representing the position of the located target on the second line $\mathrm{L}_{2}, \mathrm{~g}=2$ and $\mathrm{e}=-2$, and the two lines $\mathrm{L}_{1}$ and $\mathrm{L}_{2}$ interested in the origin.

Let $\Phi_{i}=\left(\varnothing_{i}, \varnothing_{i}\right) \in \Phi_{0}$ be a search plans and $\mathrm{E}\left[\mathrm{D}\left(\Phi_{\mathrm{i}}\right)\right], \mathrm{I}=1,2,3$

(i) suppose that $\varnothing_{1}$ consists of the points $\{-3,0,3\}$ and $\varnothing_{1}$ consists of the points $\{-2,0,2\}$

$\begin{array}{lll}\text { if } 0<\mathrm{x} \leq 3 & \text {, then } & \mathrm{D}_{2}=6 \\ \text { if }-3 \leq \mathrm{x}<0 & \text {, then } & \mathrm{D}_{1}=6 \\ \text { if } 0<\mathrm{y} \leq 2 & \text {, then } & \mathrm{D}_{4}=4 \\ \text { if }-2 \leq \mathrm{y}<0 & \text {,then } & \mathrm{D}_{3}=4\end{array}$

\section{Hence:}

\section{$\mathrm{E}\left[\mathrm{D}\left(\Phi_{1}\right)\right]=4.5$}

0(ii) suppose that $\varnothing_{2}$ consists of the points $\{-3$, $2,0,2,3\}$ and $\varnothing_{2}$ consists of the points $\{-2,-1$, $0,1,2\}$.
if $0<\mathrm{x} \leq 2$
,then
$\mathrm{D}_{2}=4$
if $2<\mathrm{x} \leq 3$
,then
$\mathrm{D}_{2}=10$
if $-2 \leq \mathrm{x}<0$
,then
$\mathrm{D}_{1}=4$
if $-3 \leq x<-2$
,then
$\mathrm{D}_{1}=10$
if $0<\mathrm{y} \leq 1$
,then
$\mathrm{D}_{4}=2$
if $1<y \leq 2$
,then
$\mathrm{D}_{4}=6$
if $-1 \leq \mathrm{y}<0$
,then
$\mathrm{D}_{3}=2$
if $-2 \leq y<-1$, then
$\mathrm{D}_{3}=6$

,Hence the expectation value can be obtained as follows :

$\mathrm{E}\left[\mathrm{D}\left(\Phi_{2}\right)\right]=4.25$

(iii) suppose that $\varnothing_{3}$ consists of the points $\{-3,-2$, $-1,0,1,2,3\}$, and $\varnothing_{3}$ consists of the points $\{-2,-$ $1,-0.5,0,0.5,1,2\}$.
if $0<\mathrm{x} \leq 1$
,then
$\mathrm{D}_{2}=2$
if $1<\mathrm{x} \leq 2$
,then 


\begin{tabular}{lll}
\hline if $2<\mathrm{x} \leq 3$ & ,then & $\mathrm{D}_{2}=12$ \\
if $-1 \leq \mathrm{x}<0$ & ,then & $\mathrm{D}_{1}=2$ \\
if $-2 \leq \mathrm{x}<-1$ & ,then & $\mathrm{D}_{1}=6$ \\
if $-3 \leq \mathrm{x}<-2$ & ,then & $\mathrm{D}_{1}=12$ \\
if $0<\mathrm{y} \leq 0.5$ & ,then & $\mathrm{D} 4=1$ \\
if $0.5<\mathrm{y} \leq 1$ & ,then & $\mathrm{D} 4=3$ \\
if $1<\mathrm{y} \leq 2$ & ,then & $\mathrm{D} 4=7$ \\
if $-0.5 \leq \mathrm{y}<0$ & ,then & $\mathrm{D} 3=1$ \\
if $-1 \leq \mathrm{y}<-0.5$ & ,then & $\mathrm{D} 3=3$ \\
if $-2 \leq \mathrm{y}<-1$ & ,then & $\mathrm{D} 1=7$
\end{tabular}

,Hence the expectation value can be obtained as follows :

$\mathrm{E}\left[\mathrm{D}\left(\Phi_{3}\right)\right]=4.69791666666$,

Hence $ø 2$ is the optimal search plan.

\section{Example 3}

If $\mathrm{X}$ is a continuous random variable that has a triangular distribution with a probability density function.

$\mathrm{f}_{1}(\mathrm{x})=\frac{1}{4}-\frac{1}{16}|\mathrm{x}|,-4<-2 \leq x \leq 2<4$

where $\mathrm{x}$ representing the position of the located target on the first line $\mathrm{L}_{1}$

$\mathrm{c}=-2$ and $\mathrm{d}=2$,

and $\mathrm{Y}$ be a continuous random variable has a triangular distribution with a probability density function.

$\mathrm{f}_{2}(\mathrm{y})=\frac{1}{4}-\frac{1}{16}|y|,-4<-4+2 \sqrt{3} \leq \mathrm{y} \leq 4-2 \sqrt{3}<4$ ,where y representing the position of the located target on the second line $L_{2}, g=4-2 \sqrt{3}$, and $\mathrm{e}=-4+2 \sqrt{3}$, and the two lines $\mathrm{L}_{1}$ and $\mathrm{L}_{2}$ are interested in the origin. We have:

$F_{1}(x)= \begin{cases}\frac{x^{2} \mid 0 x \| 12}{32} & , x<0 \\ \frac{-x^{2}+8 x+12}{32} & , x \geq 0\end{cases}$

And

$F_{2}(y)= \begin{cases}\frac{Y^{2}+8 Y+4}{32} & , y<0 \\ \frac{-Y^{2}+8 Y+4}{32} & , y \geq 0\end{cases}$

From the properties of the symmetric distribution, we can say that its cumulative distribution function satisfies. $\mathrm{v}_{1}(\mathrm{c}, \mathrm{d})-\mathrm{F}_{1}(\mathrm{x})=\mathrm{F}_{1}(-\mathrm{x})$ and $\mathrm{v}_{2}(\mathrm{e}, \mathrm{g})-\mathrm{F}_{2}(\mathrm{y})=$

$\mathrm{F}_{2}(-\mathrm{y})$

from (2.9) and using (2.15) we can get:

$E[D(\Phi)]-4 \sum_{i=1}^{\infty} a_{i}\left[v_{1}(c, d)-F_{1}\left(a_{i-1}\right)\right]+4 \sum_{j=1}^{\infty} k_{j}\left[v_{2}(e, g)-F_{2}\left(k_{j-1}\right)\right]$

Also (2.13) and (2.15) become

$a_{i+1}=\frac{\left[v_{1}\left(c_{i} d\right)-F_{1}\left(a_{i-1}\right)\right]}{f_{1}\left(a_{i}\right)}, i \geq 1$

And

$$
k_{j+1}-\frac{\left[v_{2}\left(\theta_{2} g\right)-F_{2}\left(k_{j-1}\right)\right]}{f_{2}\left(k_{j}\right)}, j \geq 1
$$

By substituting in (2.16) and (2.17) we can get:

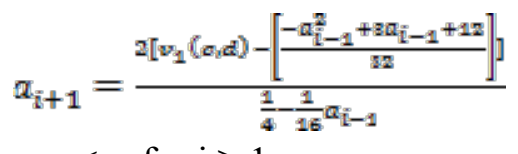

$\mathrm{a}_{\mathrm{i}-1}<\mathrm{a}_{\mathrm{i}}$ for $\mathrm{i} \geq 1$

And

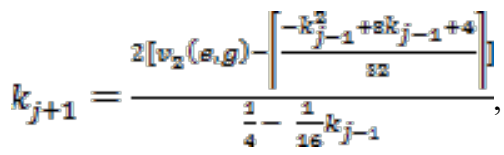

$\mathrm{k}_{\mathrm{j}-1}<\mathrm{k}_{\mathrm{j}}$ for $\mathrm{j} \geq 1$

Then the optimal search plan satisfies (2.18) and (2.19).

In table 1 we generate the steps $\mathrm{a}_{\mathrm{i}}, \mathrm{i} \geq 1$ and $\mathrm{k}_{\mathrm{j}}, \mathrm{j} \geq 1$ of the searchers which give the optimal search plan by using (2.18) and (2.19) and then ewe can find the optimal expected time. We can see from table 1 that $\mathrm{E}\left[\mathrm{D}\left(\Phi^{*}\right)\right]=3.00809002$.

Table 1

\begin{tabular}{|c|c|c|c|c|c|c|c|c|}
\hline $\boldsymbol{a}_{1}$ & $\boldsymbol{a}_{2}$ & $\boldsymbol{a}_{3}$ & $\boldsymbol{a}_{4}$ & $\boldsymbol{k}_{\boldsymbol{1}}$ & $\boldsymbol{k}_{\mathbf{2}}$ & $\boldsymbol{k}_{3}$ & $\boldsymbol{k}_{4}$ & $\boldsymbol{E}[\boldsymbol{D}(\boldsymbol{\Phi})]$ \\
\hline 2 & & & & $4-2 \sqrt{3}$ & & & & 3.26794919 \\
\hline 1.5 & 2 & & & 0.4 & $4-2 \sqrt{3}$ & & & 3.07680780 \\
\hline 1 & 2 & & & 0.2 & $4-2 \sqrt{3}$ & & & 3.00809002 \\
\hline 0.5 & 1.7142857 & 1.804687488 & 2 & 0.15 & 0.240625 & 0.37539484 & $4-2 \sqrt{3}$ & 3.297022378 \\
\hline
\end{tabular}

\section{References:}


1) A.A. Mohamed,H.A Fergany, M.A. ElHadidy, On the Coordinated Search Problem on the Plane, Istanbul University Journal of the School of Business Administration, Cilt/ Vol:xx, Say1/No:x, 2011, xx-xx Business Administration, Cilt/Vol :xx,Sayı/No:x, 2012, xx-xx.

2) A. B. El-Rayes, Abd El-moneim A. Mohamed, H. Fergani, On the generalized linear search problem,Delta Journal, No. 6. Second Part (1993), 1-10.

3) Abd El-moneim A. Mohamed, Hamdy M. Abou Gabal and Mohamed. A. El-Hadidy ,Coordinated search for a randomly located target on the plan,European Journal of pure and applied mathmatics, Vol. 2, No. 1, 2009, (97-111).

4) Abd El-moneim A. Mohamed, Hamdy M. Abou Gabal, Generalized optimal 22 search paths for a randomly located target, In: Annual Conference, Cairo ISSR, 35, Math. Statistics (2000), 17-19.

5) Abd El-moneim A. Mohamed, Hamdy M. Abou Gabal, Linear search with multiple searchers for a randomly moving target, In: International Conference for Statistices, Computer Science and Its Application, Egypt (2003), 115-124.

6) Abd El-moneim A. Mohamed, Hamdy M. Abou Gabal, Multiplicative linear search problem, Egyptian Statistical Journal, 48, No. 1 (2004), 34-45.
7) Abd El-moneim A. M. Teamah, Hamdy M. Abou Gabal and W.A. Afifi, On the

Coordinated search problem, International Journal of Applied Mathematics, 5 (2007), 627636.

8) Abd El-moneim A. M. Teamah, Hamdy M. Abou Gabal and W.A. Afifi, Double coordinate search problem .International journal of contemporary Mathematical Science 2013.

9) Diana J. Reyniers, Coordinated two searchers for an object hidden on an interval, Journal of the Operational Research Society, 46 (1995), 13861392.

10) Diana J. Reyniers, Coordinated search for an object on the line, European Journal of the Operational Research, 95 (1996), 663-670.

11) Hamdy M. Abou Gabal (2004) : Search Plans With Multiple-Searchers for Lost Targets, $\mathrm{Ph}$. D. Thesis, Tanta University.

12) L.D Stone. Theory of Optimal Search, volume 118 of Mathematics in science and Engineering. Academic Press, New York, 1975.

13) F. Bourgault, T. Furukawa, and H.F. Durrant-Whyte, Optimal search for a lost target in a Bayesian world. S. Yaut et al. (EDS.):Field and Service Robotics (2006), 209-222.

14) F. Bourgault, et al., Coordinated decentralized search for a lost target in a Bayesian world, Proc. IEEE/RSJ Int. Conf. Intel. Robot. Sys., (2003).

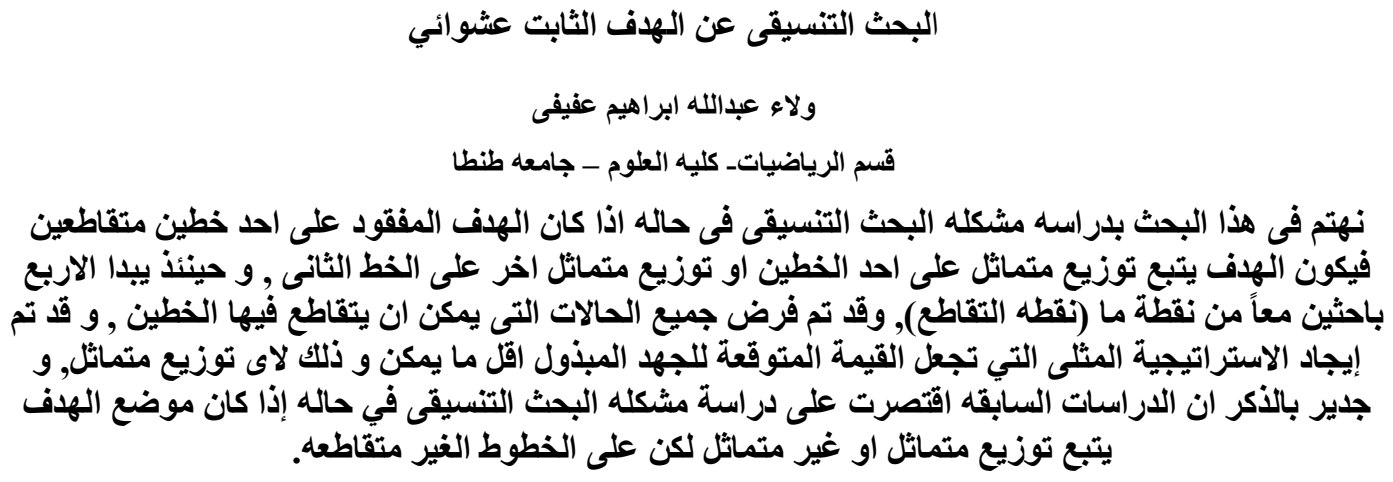

